\title{
Discursos sobre a leitura: uma análise de vídeo-campanhas em prol dessa prática
}

Simone Garavello Varella"

Luzmara Curcino"

\section{Resumo}

Este artigo, depreendido de algumas constatações a que chegamos a partir de nossa dissertação de Mestrado, empreende o levantamento de algumas representações de práticas de leitura contemporâneas por meio da análise de vídeos de incentivo à leitura postados no site do YouTube. Apoiando-nos em princípios da Análise do Discurso de linha francesa e da História Cultural da Leitura, desenvolveremos nossa análise de modo a descrever eventuais representações discursivas que se fazem da leitura nesses vídeos que visam promovê-la, assim como descreveremos as representações de leitor que os produtores desses vídeos fazem do público a que se dirigem. Portanto, buscamos em nossa pesquisa analisar alguns indícios, inscritos nas produções desses vídeos, de projeções de práticas de leitura, de modo a refletirmos sobre um dado imaginário que partilhamos hoje em dia acerca do que é a leitura, de como ela deve ser exercida, do que é ser um bom leitor e de como proceder para promovê-la.

Palavras-chave: Discursos sobre a Leitura. Campanhas de incentivo. Vídeos do YouTube.

\section{Introdução}

"Percorrer a história da leitura no Brasil é percorrer a história de um lamento". Assim afirma a pesquisadora Márcia Abreu (2001b), analisando textos escritos por viajantes europeus tomados como base para reconstituir as condições culturais brasileiras anteriores à independência. Esses registros, de acordo com a autora, fundaram um modo de interpretar o país, que atravessou os séculos seguintes e, poderíamos dizer que, em certa medida, perdura até hoje.

\footnotetext{
Doutoranda pelo Programa de Pós-Graduação em Linguística da Universidade Federal de São Carlos. E-mail: sgvarella@hotmail.com

* Doutora em Linguística e Língua Portuguesa pela Unesp/FCLAr - Araraquara - SP. Professora Adjunta do Departamento de Letras e do Programa de Pós-graduação em Linguística da Universidade Federal de São Carlos. E-mail: luzcf@ufscar.br
}

Data de submissão: jul. 2014 - Data de aceite: ago. 2014 http://dx.doi.org/10.5335/rdes.v10i2.4157 
Neles é possível verificar um antagonismo entre a vida letrada e a cultura no Brasil colônia em relação à Europa. As pinturas oitocentistas, analisadas pela autora, são uma das fontes materiais de representação dessa "imagem de erudição e estabilidade [composta] a partir da acumulação de símbolos de sucesso intelectual: uma biblioteca particular, livros espalhados e abertos" (ABREU, 2001b, p. 148 , grifos nossos) que caracterizava a imagem dos letrados europeus, em oposição às pinturas que representaram os intelectuais brasileiros, de forma primitiva e precária.

Assim, compartilhando um imaginário predominante no período, em contexto europeu, valorativo e etnocêntrico, acerca da leitura e do leitor, ao se depararem com padrões culturais e econômicos diferentes dos que eram relativamente comuns às metrópoles, os viajantes europeus, segundo Abreu (2001b) registraram suas impressões da presença da cultura letrada na colônia apresentando as precárias condições de vida da população, a inexistência ou a inadequação das escolas brasileiras, $o$ reduzido número de livreiros e a má qualidade de seus estoques bem como o desinteresse pela leitura por parte dos habitantes locais.

A crença em uma "insuficiência cultural" brasileira fez com que ainda no Século XIX surgissem comentários como o que segue:
O povo brasileiro - não é sem mágoa que o dizemos - posto que deva desempenhar em período talvez não muito remoto papel importante no teatro do mundo, não está ainda preparado para consumir o livro, substancial alimento das organizações viris e fortemente caracterizadas. Faltam-lhe as condições de gosto, instrução, meios, saudável direção de espírito, sem as quais não se pode cumprir a livre obrigação que equipara o artesão ao capitalista, o operário ao literato, o pobre ao milionário - a de comprar, ler, entender verdades ou ideias coligidas em um volume, cuja leitura demanda fôlego e cujo estudo requer tempo de que o povo em geral não dispõe (LAJOLO e ZILBERMAN apud ABREU, 2001b, p. 140, grifos nossos).

Registros de fontes diversas (cartas pessoais, notas em jornais, obras literárias, pinturas, etc.) desse período, assim como textos contemporâneos muito distintos manifestam a força que certos discursos sobre a leitura apresentam. A remanência, em textos da atualidade, da ideia de "crise" pela qual passa a prática de leitura no Brasil não é, portanto, nova. Essa crença é em grande parte tributária do modo como essa prática foi concebida historicamente e do modo como foram se constituindo os dizeres autorizados se não produzidos originalmente, ao menos tendo sido bastante reiterados a partir do parâmetro idealizado para tal prática distintiva na Europa dos Séculos XVIII e XIX. Difundida então como atividade individual e solitária, como prática que para sua realização faz-se necessário gosto, instrução, meios e saudável direção de espírito, ela não poderia, como vemos se afirmar no passado e no presente, vingar no Brasil, onde a falta regula e assombra os dizeres 
sobre nós e de nós sobre nós mesmos. Tal pressuposto e trauma vêm orientando ao longo do tempo esse imaginário do déficit, essa síndrome de "primo pobre" que nos acomete.

Entre os fatores citados, o principal déficit evidenciado e afirmado ao longo dos tempos e que parece perdurar na atualidade, conforme se apresenta em dados de pesquisas que mensuram a "quantidade de leitura" dos brasileiros ${ }^{1}$, destacam-se como índice dessa carência, especificamente, os dados relativos ao consumo/posse do "livro" (primordialmente sob a forma impressa), objeto cujo valor simbólico é historicamente reafirmado, reforçado e por isso concebido como forma de distinção sociocultural daqueles que o possuem, utilizam e/ou ostentam. Conforme afirma Lajolo (2002, p. 34), "a existência desses leitores de carne e osso manifesta-se de diferentes maneiras, sendo a mais concreta de todas expressa em cifrõe\$ e cifrinha\$”.

Desse modo, "é preciso examinar com cuidado os discursos que alardeiam o fracasso da cultura letrada no Brasil, examinando o lugar de onde eles partem e seus pressupostos" (ABREU, 2001b, p. 142). Esse exame não pode se furtar da análise da variação nas formas desse objeto cultural, dos dizeres dispersos e de diferentes origens acerca desse objeto e por extensão das práticas de sua apropriação e daqueles que os possuem/ utilizam/ostentam. Nessa "economia" discursiva encontra-se o conjunto de dizeres voltados para o reforço e a manutenção da promoção da prática de leitura e de seu objeto mais emblemático, o livro. Assim, articuladamente, os esforços de distinção sociocultural dos sujeitos, a afirmação do déficit cultural do outro, a eleição de objetos e práticas símbolos dessa distinção e desse déficit, a "constatação" e reiteração da "diferença" como "crise" constituem um dado discurso sobre a leitura cujas origens são imprecisas, assim como de qualquer discurso, mas cuja difusão e registros esparsos ou concentrados em certos períodos e locais nos permitem localizar ainda que temporariamente certas repetições e diferenças nos dizeres, nas práticas, portanto, no discurso.

Desses dizeres e fazeres constitui-se a ideia geral de que o brasileiro não lê, ou de que o brasileiro lê pouco e mal, atestando não apenas a situação de crise em que se encontra a leitura em terras tupiniquins. Talvez um dos tipos mais eloquentes de texto em que se afirma a crise, até mais do que aqueles que a tematizam explicitamente, sejam aqueles que assumem a responsabilidade de promovê-la, de incentivá-la. Assim, muitos e variados setores da sociedade tomam para si a responsabilidade pela criação e veiculação de campanhas em prol da leitura, valendo-se de diferentes formatos e meios, mas compartilhando de um ponto em comum, a saber, de dizeres de um tipo específico, que segundo os estudiosos da leitura Barzotto e Britto (1998) e Britto (1999) corresponderiam a "mitos", pela semelhança de seus funcionamentos. Tal como o "mito", alguns 
dizeres adquirem uma força de verdade atemporal porque se autonomizam da própria realidade e parecem sintetizar tudo o que se poderia dizer de verdadeiro sobre algo. $\mathrm{O}$ que se diz sobre a leitura e sobre o leitor, assim como a maneira desse dizer, como bem constataram os autores, funciona de modo semelhante à produção e circulação de um "mito" cuja força encontra-se exatamente no poder de oferecer uma explicação simples, sintética, o que garante sua reiteração, a qual e essa, por sua vez, assevera sua força de verdade.

Os dizeres sobre a leitura têm história e memória, logo, suas representações, apesar de variadas, podem ser condensadas em um número relativamente pequeno de "enunciáveis" sobre a leitura, como os que os autores destacam: prática redentora e transformadora da realidade e fonte de prazer e de ilustração. Sem dúvida, é esse consenso quanto ao poder da leitura que se encontra na origem da necessidade de promovê-la e se reforça e perpetua nas formas de sua promoção que se ocupam, como constatam Barzotto e Britto (1998) de orientar, mas também de convencer, por mais estranho que pareça, leitores já convencidos acerca da importância dessa prática.

Esse imaginário que se perpetua sob a forma do funcionamento do "mito" é corolário, segundo Abreu (2001a), de uma "associação entre leitura e enobrecimento do sujeito [que] foi construída historicamente, tendo recebido forte impulso com a ascensão da burguesia" e que remonta ao final do Século XVIII e ao longo do XIX, uma vez que assim como as casas grandes e confortáveis, os livros e as grandes bibliotecas também foram alçados a formas de manifestação de sucesso pessoal, de justificativa das diferenças, e como ícone de distinção.

$\mathrm{Na}$ atualidade, esses discursos sobre a leitura, cujo funcionamento se assemelha à forma de produção e circulação de mitos, são um exemplo bastante emblemático da remanência de traços do olhar eurocêntrico de eruditos que registraram suas impressões da cultura do Brasil nos primeiros séculos e também da remanência do imaginário burguês do Século XVIII e XIX, como buscaremos refletir na análise a que nos propomos nesse artigo de certas formas de promoção da leitura.

Com vistas a empreender o levantamento de representações que se fazem das práticas de leitura de brasileiros na contemporaneidade, em consonância com o objetivo geral do grupo de pesquisa LIRE, ${ }^{2}$ analisamos, no presente trabalho, uma modalidade específica de campanhas de promoção da leitura, a saber: aquelas que circulam em meio eletrônico, sob a forma de vídeos de curta duração, disponíveis no site do YouTube. ${ }^{3}$ Nossa análise restringiu-se a levantar certas semelhanças e diferenças existentes na produção dessas vídeo-campanhas, dividindo-as, particularmente, em duas categorias: a de Campanhas propriamente ditas, e a de Protocampanhas. Com essa classificação geral e inicial procedemos a organização de nosso corpus de pesqui- 
sa de mestrado (do qual apresentamos uma pequena amostra neste artigo), de modo a buscar recorrências internas a esses dois conjuntos e também externas na relação de um conjunto com o outro. Conforme constatamos, há uma regularidade bastante acentuada no que se diz e no modo como se promove a leitura nesses textos, o que seria tributário, como discutiremos, desse funcionamento socio-histórico dos discursos. Há, no entanto, diferenças quanto aos modos de formulação e de circulação, enfim, quanto ao modo de funcionamento técnico, institucional, autoral dos textos das vídeo-campanhas desses dois conjuntos que constituem nosso material de pesquisa, que nos cabe mensurar a partir da análise das estratégias de escrita (de produção) de que se valem.

\section{Fundamentação teórica}

Valer-nos-emos, em nossa análise, do aporte teórico da Análise de Discurso, em especial, de considerações feitas por e a partir de textos fundamentais de Michel Pêcheux e Michel Foucault, que nos orientam na identificação de discursos que subsidiam a produção desses vídeos e na descrição de seu funcionamento com vistas à análise das diferentes materialidades discursivas que os compõem, cuja seleção e emprego têm impacto sobre os efeitos de sentido que potencialmente podem ser gerados em sua interpretação; na observação, enfim, dos enunciados verbais e não verbais que se repetem, reiteram-se, alteram-se na produção desses vídeos e que se constituem em um campo associado sincrético de relações semânticas.

Apoiamo-nos ainda em alguns legados da História Cultural da Leitura, tal como desenvolvidos por Roger Chartier, em particular, no que se refere à noção de representações tendo em vista que elas [as representações]

[...] não são simples imagens, verídicas ou enganosas, do mundo social. Elas têm uma energia própria que persuade seus leitores ou seus espectadores [de] que o real corresponde efetivamente ao que elas dizem ou mostram (CHARTIER, 2011, p. 27).

Assim, quando se enuncia que "A leitura transforma sua vida" ou "Ler pode garantir seu futuro", ${ }^{4}$ essas são representações que se fazem das práticas de leitura de tal modo enraizadas no imaginário coletivo e compartilhadas como verdadeiras que sua afirmação, reiteração e interpretação se automatizam e ganham a dimensão das coisas óbvias. Assim, essas representações, que são discursivas, que funcionam discursivamente, manifestam-se, tal como o discurso, nas formas materiais de objetos culturais de leitura (livros, móveis, revistas, jornais), nos textos (que tematizam ou não a leitura, ficcionais ou científicos, pelo modo como são escritos ou pelo que dizem), nas declarações de sujeitos, de instituições (sejam eles leitores ou não, sejam elas ligadas diretamente ou não à leitura).

Dedicando-nos à análise dessas vídeo-campanhas, buscamos compre- 
ender certas formas de emergência de discursos sobre a leitura que circulam na atualidade, considerando, segundo Foucault (2012), as formas de controle que se exercem sobre essa emergência e que correspondem a uma "ordem discursiva" que regula o que pode e deve ser dito e sob que formas o dizer pode ser manifesto. É a "ordem do discurso" que atribui o status de verdadeiro a um dizer, em detrimento de outros, que autoriza e desautoriza os sujeitos a se apropriarem desses dizeres, que, enfim, determina quais são os dizeres que permanecerão para além de sua enunciação e que outros desaparecerão tão logo finda a sua elocução.

\section{Procedimentos metodológicos}

Para a constituição do corpus efetivo de análise de nossa pesquisa de mestrado, nosso levantamento dos vídeos de incentivo à leitura deu-se por meio da busca por palavras-chave como leitura, incentivo à leitura e importância da leitura, na barra de pesquisa do site do YouTube. Essa busca nos apresentou um número significativo de vídeos, o que já indicia a relevância de que a prática de leitura e a sua promoção dispõem entre nós, hoje. Tal busca também foi facilitada por uma ferramenta do próprio site que permite ao usuário, ao selecionar um vídeo, ter à disposição uma lista de outros vídeos com conteúdo semelhante. Depois de feito o levantamento dos vídeos, proce- demos à seleção daqueles que figurariam no corpus de nosso trabalho, baseados no levantamento de certas regularidades na produção e circulação primeira dos vídeos quanto ao "que" enunciam, que discursos sustentam essas campanhas, que valores e ideias reproduzem, mas também quanto ao "como" enunciam, que estratégias de escrita são empregadas na produção dos vídeos (escolhas lexicais, frasais ou imagéticas), que sujeitos e que instituições assumem a enunciação.

A seleção desses vídeos, sua classificação inicial em Campanhas e Protocampanhas, sua conjunção em subgrupos com outros vídeos, considerando as semelhanças constatadas no que dizem e no modo como o fazem, consistiu nos procedimentos que adotamos de construção, organização e análise do corpus, tendo em vista assinalar certas representações de práticas de leitura que compartilham.

Dessa forma, nosso corpus de análise compôs-se de 35 vídeos. Desses, conforme nossa classificação preliminar, nove se inseriram na categoria Campanhas e 26 na categoria Protocampanhas, postadas no YouTube entre os anos de 2007 e 2012 e com duração variável de 0:20 segundos a 6:00 minutos, aproximadamente. ${ }^{5}$

A opção por analisar os vídeos nesse período se deveu ao fato de no final de 2006 o Google ter comprado essa plataforma de compartilhamento de vídeos, o que, possivelmente, popularizou-a junto aos internautas, e o ano de 2012 coincide com nosso primeiro ano de Mestrado, 
época em que coletamos os vídeos de incentivo à leitura.

A classificação inicial e mais genérica dos vídeos em prol da leitura em Campanhas e Protocampanhas adveio da nossa constatação de diferenças importantes tanto do ponto de vista da produção quanto da forma de circulação original desses vídeos. Embora essa classificação possa sinalizar para uma distinção valorativa, em que uma é classificada como menor em relação à outra, nosso intuito foi o de tornar mais visíveis as diferenças de suas motivações, de suas estratégias de escrita, das instituições que as validam ou não, das formas de circulação distintas tanto do ponto de vista técnico quanto simbólico. Para que pudéssemos descrever o funcionamento discursivo desses vídeos em prol da leitura que, se se assemelham quanto ao "que"enunciam acerca da leitura, o mesmo não se pode dizer em relação ao modo como o fazem, o modo como circulam, os recursos de que se valem, as instituições a que pertencem, as posições sujeito a partir das quais enunciam.

São a essas variações que gostaríamos de dar relevo e demonstrar como a "ordem discursiva" se estabelece não apenas sobre o "que" se pode e se deve enunciar sobre a leitura, mas também determina (e produz sentido por essa determinação) o modo e as formas de dizer (na escolha do gênero, nas posições enunciativas assumidas pelos sujeitos, na credibilidade ou não que esses enunciados adquirem porque foram produzidos por indivíduos anônimos ou por instituições de renome, de forma leiga ou profissional, para circular em mídias tradicionais ou para circular exclusivamente via internet etc.). Se, graças às remanências do que se diz sobre a leitura nesses vídeos pudermos de início crer que dizem a mesma coisa $\mathrm{e}$ que seu dizer funciona de maneira semelhante, contudo, as distintas estratégias de escrita mobilizadas nos permitem aceder a algumas representações de práticas da leitura contemporâneas à medida que, valendo-se do modelo de enunciação predominante das Campanhas, as Protocampanhas atualizam-no de maneira particular como pretendemos demonstrar nas análises.

Com vistas a dar visibilidade às diferenças e semelhanças dos vídeos do corpus, aqueles que designamos como Campanhas correspondem aos vídeos produzidos por instituições, em sua maioria ligadas ao universo dos livros tais como bibliotecas, editoras, instituições de ensino superior, ou outras instituições, como bancos, que compartilham valores similares em relação à leitura e se advogam a responsabilidade de promovê-la e/ou objetivam gozar do prestígio que a promoção dessa atividade gera para seus produtos ou fins comerciais. Já os vídeos designados como "Protocampanhas" são aqueles produzidos por indivíduos, em sua maioria, não especialistas, seja em resposta a uma demanda escolar (como requisito para obtenção de notas em uma disciplina) seja por iniciativa espontânea ou não declarada. 
Campanhas e Protocampanhas também se diferenciam em quatro outros aspectos, como demonstraremos, posteriormente, nas análises. Tais aspectos referem-se à motivação de sua produção, a sua validação no que diz respeito ao gênero (campanha), ao grau de especialização de sua elaboração e aos meios para os quais originalmente foram feitas, já que, embora todos esses vídeos estejam disponíveis no site do YouTube, alguns deles foram produzidos para circular inicialmente em outros meios de comunicação mais tradicionais como a TV aberta, e apenas posterior ou concomitantemente foram postados nesse site de compartilhamento de vídeos.

Com vistas a tornar mais acessível às amostras do corpus de análise, que por sua natureza de vídeo oferecem dificuldades de registro sob a forma de um texto impresso, optamos por "congelar" e "colar" algumas de suas imagens de modo a exemplificar algumas sequências narrativas e as estratégias de escrita utilizadas pelas campanhas. Também nos preocupamos em indicar seu endereço de origem no YouTube, para uma eventual consulta ao vídeo em sua completude.

Com base na categorização em Campanhas e Protocampanhas que de início desenvolvemos, e com finalidade didática, empreendemos uma subcategorização dos vídeos do corpus, tendo em vista as variações nas representações da leitura exploradas e manifestas nesses vídeos que, embora partilhem valores eufóricos acerca da leitura e se proponham a promover essa prática, o fazem explorando temas específicos, e são esses temas específicos (ou preponderantes) explorados nos vídeos que nos exigiram subcategorizar os vídeos de Campanhas e Protocampanhas, segundo a exploração e a força de dois eixos temáticos principais porque mais reiterados que, conforme dissemos anteriormente, referem-se às regularidades encontradas no que tange às representações das práticas de leitura veiculadas nesses vídeos. São eles: "Quem lê, progride" e "Quem lê, viaja". ${ }^{6}$ No interior desses dois principais eixos ou temas recorrentes, também encontramos outros enunciados remanentes e que sintetizam representações das práticas de leitura, intrínsecas ou complementares às representações temáticas mais recorrentes. Para o artigo que ora se apresenta, visamos à apresentação de um desses eixos temáticos, a saber, "Quem lê, progride", mais especificamente as indicações acerca do "que/como" é indicado que se leia para progredir.

Algumas peculiaridades apresentadas no momento dessa subcategorização deixaram mais evidentes certas características das Campanhas e das Protocampanhas que corroboram nossa hipótese de que tais produções não podem ser tomadas genericamente como vídeos de incentivo à leitura. No caso das Campanhas, por serem em menor número, e de menor duração em função sobretudo da imposição do meio de circulação original (tempo na TV), elas seguem um script 
que sustenta, em sua maioria, uma única afirmação (ainda que genérica) acerca da leitura. Assim, a identificação nessas Campanhas do predomínio de um dos eixos temáticos supracitados mostrou-se mais simples. No que diz respeito aos vídeos inseridos na categoria Protocampanhas, essa identificação foi mais problemática, uma vez que não apresentam uma sequência narrativa muito bem estruturada o que, aliado à sua duração, em geral mais extensa do que a dos pertencentes à primeira categoria, somada ao fato de que esses acumulam diversas representações das práticas de leitura acabaram por tornar mais complexa sua subclassificação, haja vista a necessidade de pensarmos em conjuntos que abarcassem a heterogeneidade de seus discursos e reproduzissem o imaginário geral que se faz presente nesses vídeos.

\section{Resultados e análise}

Os vídeos inseridos no eixo temático "Quem lê, progride" partilham um imaginário da leitura como prática redentora e transformadora da realidade social. Pudemos verificar que as paráfrases efetuadas nos enunciados que compõem os vídeos são sempre voltadas a responder, em certa medida, a um "o que/como (de que modo)" se deve ler e "por que" a leitura é compreendida desse modo.

No primeiro caso, as "respostas" à questão "o quê? como?" sinalizam para uma enunciação propositiva, com a reiteração/indicação de formas de ler con- sagradas, validadas socioculturalmente de modo a reafirmar e atestar o ideal (se não o único modo de) exercício dessa prática, bem como indicar a postura esperada dos leitores frente à leitura (ao que devem ler, ao como devem ler) para que tenham acesso aos benefícios dessa prática (ao por que devem ler). Dito de outra maneira, os enunciados parafrásticos de "Quem lê, progride". funcionariam de modo a responder e a produzir distinções entre sujeitos e práticas a partir das perguntas: "Quem lê o que se deve ler, progride." e "Quem lê como se deve ler, progride".

Nas Campanhas pudemos constatar que a prática de leitura difundida/defendida é aquela prioritária ou exclusivamente realizada pelo consumo de livros impressos (especialmente de um dado gênero, para fins de entretenimento) e empreendida frequentemente pelos leitores (como hábito).

Embora reproduza a relação direta e por isso exclusiva entre a leitura e o livro (ou seja, só se reconhece como leitura de valor, aquela de livros), tendem a vincular os "ganhos" da leitura, em sua maioria, a ganhos de ordem quantitativa e/ou mais material, ou seja, ganhos intelectuais, profissionais, econômicos. É o caso, por exemplo, de uma série de vídeos que constitui a Campanha produzida pelo Banco Itaú, para divulgar sua marca por meio de ação de doação de livros infantis, com o mote "Leia para uma criança". A campanha consiste na vinculação do nome da marca a uma atividade com valor simbólico agregado (doação de 
$\operatorname{livros}^{7}$, incentivo à leitura, promoção da leitura para crianças etc.). O primeiro vídeo da série, intitulado "Itaú - Sala de Espera ${ }^{8 ”}$, explora a representação da leitura, segundo a qual é preciso ler livro impresso, e frequentemente.

Nesse vídeo, a leitura com valor simbólico é aquela de gêneros de ficção, com fins de entretenimento, a partir de livros impressos. Para tanto, a estratégia de escrita utilizada foi a de apresentar uma série de personagens de histórias infantis tais como Chapeuzinho Vermelho, Lobo Mau, Cinderela, um sapo com vestes de príncipe, entre outros personagens, todos em uma sala de espera, aguardando ser chamado, tal como enunciado verbalmente no vídeo "Tem um monte de histórias esperando para serem lidas" e reiterado pela relação em princípio homológica estabelecida com o que é enunciado imageticamente uma vez que, na sequência, e ao toque de um alarme, a personagem Cinderela se levanta e caminha rumo a uma sala na qual, posteriormente, é possível ver sua imagem estampada em uma das páginas de um livro que o pai lê para a filha.

Abaixo a transcrição do vídeo na totalidade:

[Narrador] Tem um monte de histórias esperando para serem lidas. Só depende de você. [voz do mago dirigindo-se à cinderela] Sua vez! [Narrador] Leia para uma criança. Histórias ajudam no aprendizado e desenvolvimento infantil. Mude, e conte com o Itaú pra mudar com você.

O enunciado "Tem um monte de histórias esperando para serem lidas", se estabelece em uma relação homológica por analogia com o que é enunciado imageticamente. Também reitera a representação da leitura, segundo a qual é preciso ler sempre, frequentemente, mas não qualquer coisa, uma vez que pela especificidade do público a que se dirige, há a sugestão de ler textos de ficção, em específico, os contos de fadas.

No tocante à relação de interlocução estabelecida, nessa Campanha, a estratégia de escrita empregada é a de convocação dos pais ou responsáveis para lerem para crianças, tal como enunciado verbalmente "Só depende de você". Essa convocação de pais e responsáveis também fica evidente pelo slogan que norteia as Campanhas dessa ação de doação de livros infantis "Leia para uma criança”. O enunciador assume, então, uma posição hierárquica em relação ao enunciatário quando se coloca como aquele que sabe e aconselha os demais, e quando pressupõe a necessidade desse conselho pela hipotética ausência da prática incentivada entre aqueles a quem se dirige.

Figura 1: Extraída do vídeo "Itaú - Sala de Espera"

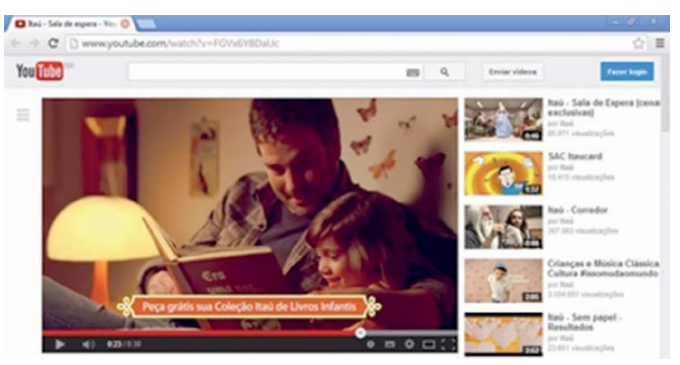

Como dissemos anteriormente, Campanhas e Protocampanhas guardam semelhanças no tocante aos discursos veiculados em ambas as produções au- 
diovisuais, discursos cuja reiteração foi responsável pelo relativo consenso que há em relação ao que dizer atualmente sobre a leitura. No entanto, se nas Campanhas as representações das práticas de leitura tendem a ser mais tradicionais, insistindo, por um lado, na relação direta e exclusiva entre leitura e livro impresso, na representação de textos de origem ficcional e de entretenimento, e na ênfase no aspecto quantitativo, ou seja, quanto mais livro lido melhor, nas Protocampanhas, essas representações se avizinham de outras.

Na Protocampanha denominada "Incentivo à Leitura Universitária", ${ }^{9} \mathrm{em}$ consonância com os discursos veiculados nas Campanhas, essa alegada crise de leitura é apresentada em decorrência da competição com outros meios de comunicação, nesse caso, o computador. A competição entre o livro impresso e o computador, ou o universo virtual, é, então, construída por meio da atualização dos discursos acerca da sustentabilidade, tão caros na contemporaneidade. Desse modo, o vídeo é iniciado com a imagem de uma tomada na qual é plugado o carregador de bateria de um computador. $\mathrm{Na}$ sequência há uma referência ao gasto de energia " 200 Watt". Posteriormente é mostrado um livro aberto e uma mão que muda suas páginas e na continuidade a mesma referência ao gasto calórico "1 Caloria".
Figura 2: Extraída do vídeo "Incentivo à Leitura Universitária"

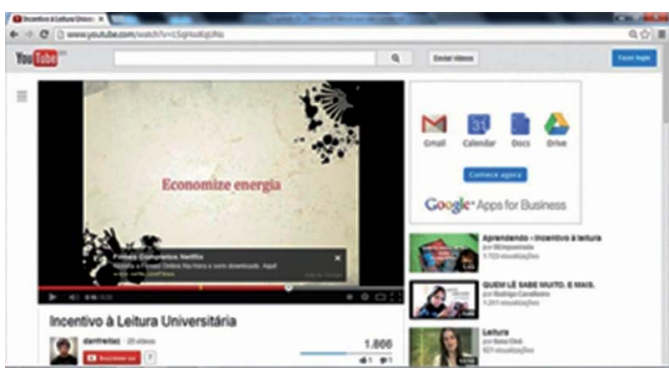

Figura 3: Extraída do vídeo "Incentivo à Leitura Universitária"

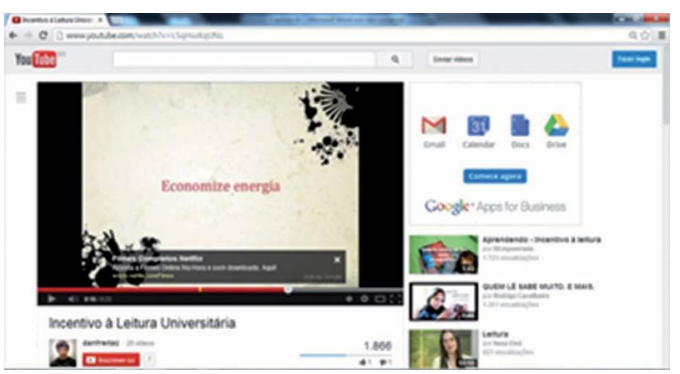

Assim, valendo-se de discursos sustentáveis evidenciados tanto pela referência aos diferentes gastos energéticos em uma e em outra atividade, quanto pela utilização do verbo economizar em seu modo imperativo Economize, para atestar a prática de leitura que crê legítima, as estratégias de escrita dessa Protocampanha também nos permitem outras reflexões. Primeiramente a pressuposição de que os universitários não leem, porque ficam muito tempo no computador, como se as leituras realizadas em tela também não fossem uma sua modalidade. Em segundo lugar, acerca da concepção de cultura que é reproduzida nesse vídeo. 
Bauman (2012, p. 90), buscando explicar o conceito hierárquico de cultura e o modo como o mesmo indica, de certa forma, uma falta de reflexão acerca do que efetivamente pode ser compreendido por cultura, afirma que:

Tendemos a classificar aqueles com quem travamos contato segundo seu nível cultural. Se o distinguimos como uma "pessoa culta", em geral queremos dizer que ele é muito instruído, educado, cortês, requintado acima de seu estado "natural" nobre. Presumimos tacitamente a existência de outros que não possuem nenhum desses atributos. Uma "pessoa que tem cultura" é o antônimo de "alguém inculto".

Podemos constatar que o termo cultura empregado nessa Protocampanha repercute, de certo modo, essa forma de compreensão do próprio termo. Contudo, o traço distintivo entre pessoas consideradas cultas e incultas remete à quantidade de leitura efetuada sob a forma do livro impresso, embora sem uma indicação direta sobre qual gênero de leitura está em jogo, em detrimento do tempo gasto em frente ao computador.

Sistematicamente, a maioria dos vídeos postados no YouTube oferece à pergunta "o que ler?", a mesma resposta: ler, ler sempre, livros impressos, de ficção, de preferência de literatura clássica. Por vezes circulam referências a obras de outros gêneros, mais contemporâneos, em especial a títulos de Best-sellers. Isso sinaliza, conforme se pode observar nos vídeos das Protocampanhas intituladas "A importância da leitura", ${ }^{10}$ e "Manifesto à Leitura", ${ }^{11}$ por um lado, a força do imaginário tradicional sobre a leitura e sobre a lógica da distinção que se estabelece entre quem lê e quem não lê, da compreensão de que a leitura deve ser uma prática realizada sempre, por prazer, e que para isso é preciso ler apenas textos ficcionais, de preferência já consagrados; por outro, a pressão do mercado como fonte difusora de títulos, que se vale do valor simbólico do livro, para promover Best-sellers atuais.

Figura 4: Extraída do vídeo "A importância da leitura"

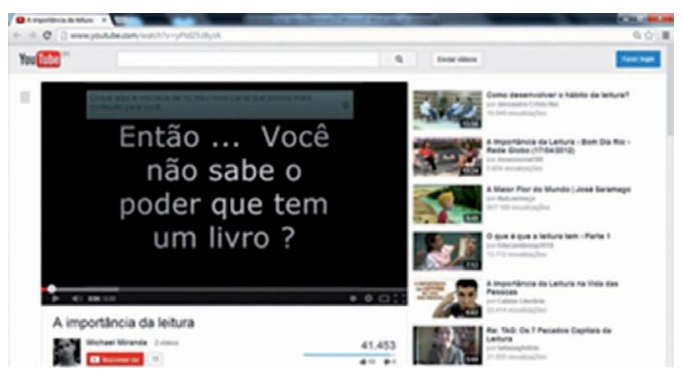

Figura 5: Extraída do vídeo "Manifesto à Leitura"

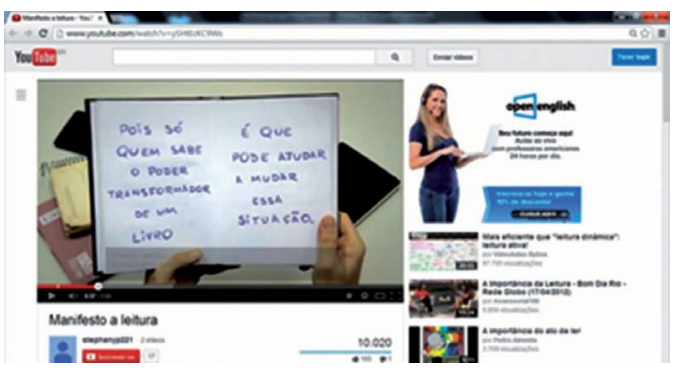

Outro aspecto semelhante entre esses dois vídeos é a atribuição ao livro de um poder redentor e transformador da realidade social. Também há a explícita indicação sobre o gênero que assegura essa transformação: o literário. Na Pro- 
tocampanha "A importância da leitura" essa indicação se dá tanto pela relação estabelecida entre o enunciado verbal Mas se você usá-lo de forma ideal e o enunciado imagético de um livro aberto no qual está escrito Literatura, palavra da qual sai uma luz, quanto pela apresentação de uma série de nomes de autores nacionais e internacionais da alta literatura ou literatura erudita. Essa forma ideal de se valer dos livros é que faz com que a leitura seja redentora e transformadora da realidade social Você evolui e sua vida também...

Contudo, ainda que a estratégia de escrita empregada nesse vídeo seja a de defesa ou de afirmação da importância da leitura por meio de uma tentativa de sedução, o que por um lado não poderia ser diferente já que se trata de uma campanha de incentivo à leitura, estabelece-se uma relação curiosa entre o que é enunciado verbal e imageticamente quando se intenta exemplificar os mundos, por exemplo, de ação e aventura ou as terras mágicas a que possivelmente serão apresentados aqueles que se aventurarem pelo mundo da leitura, pois para tanto utilizam-se excertos de filmes de terror, de ficção científica ou somente de ficção, como uma encenação do "Auto da Barca do Inferno" de Gil Vicente e também da minissérie "Capitu" baseada na obra Dom Casmurro de Machado de Assis e exibida pela Rede Globo, ao invés, por exemplo, de serem utilizados excertos de livros considerados pelos idealizadores da campanha como grandes obras literárias. De modo que há o que poderíamos tomar como uma relação de contradição uma vez que se quer promover a leitura, e, por conseguinte o livro, ao mesmo tempo em que a estratégia de escrita utilizada nesses vídeos privilegia o uso de exemplos que se valem de vídeos cinematográficos ou televisivos, contradizendo o que é enunciado verbalmente e, por essa contradição, revelando um traço do perfil leitor da atualidade, exposto a um número maior de objetos culturais, acostumado às adaptações audiovisuais de livros.

Além disso, os gêneros, títulos e autores citados indiciam o que leem e o porquê leem (condições socioculturais) esses leitores que assumem a tarefa de promover a leitura. Suas referências a títulos clássicos demonstram o papel da escola na indicação de leituras que constituem um currículo de base (Machado de Assis, Aluísio de Azevedo). Já suas indicações de Best-sellers de gêneros ficcionais voltados para o público jovem (sagas, trilogias, thrillers etc.), e a referência às adaptações fílmicas, sinalizam essa outra instituição promotora da leitura entre os jovens: o mercado de best-sellers, cujo motor comercial é a produção de megaproduções fílmicas para esse segmento.

Vemos que, diferentemente das Campanhas, a estratégia de escrita empregada nas Protocampanhas para convocar os leitores a gozarem dos benefícios propiciados pela leitura listados é a de aconselhar por meio de uma relação 
de intimidade com o interlocutor, evidenciada, por exemplo, pela linguagem informal tá (verbo estar), quanto pelo que chamamos genericamente de objetividade do conclame/convocação expresso no vídeo "Ler em 15 lições"12 (tal como imagem abaixo), uma vez que esse modo direto é a forma como normalmente nos comunicamos com pessoas próximas.

Figura 6: Extraída do vídeo "Ler em 15 lições"

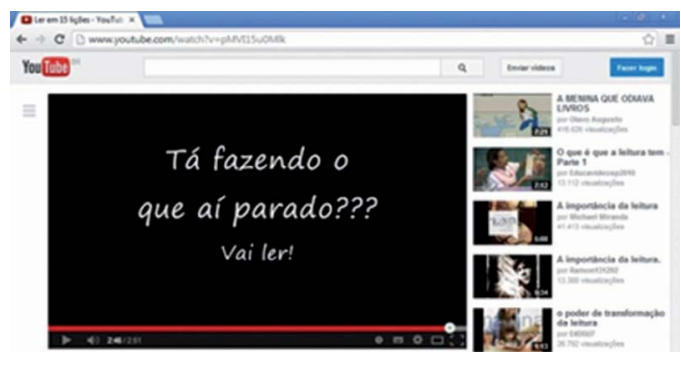

Contudo, se nessa Protocampanha o aconselhamento se dá por um viés de inclusão, que poderia ser traduzido em linhas gerais como "não fique fora dessa já que todo mundo está lendo" o mesmo não ocorre com o vídeo intitulado "A importância da leitura" ${ }^{13}$ Essa Protocampanha tem uma construção muito semelhante (quase idêntica) à do vídeo homônimo, já apresentado nesse tópico de análise. Em ambas, a leitura é apresentada como traço distintivo entre detentores e não detentores de conhecimento, tal como reproduzido abaixo:

Não seja mais um na multidão...Seja um leitor! Não seja mais um entre muitos cegos... Seja um leitor!
Assim, o modo de se destacar dos demais perante uma generalizada suposta falta de conhecimento, consequência direta da falta de leitura, é se tornar leitor.

Com relação a esse imaginário contemporâneo do que seja "ser leitor", tido como um traço distintivo entre as pessoas à medida que seria avalista, entre outras coisas, de uma redenção individual, Britto (1999) afirma que

[...] assim como não faz sentido dizer que alguém, por ser cliente, eleitor, usuário ou assegurado, torna-se melhor ou pior, mais ou menos crítico, também não faz sentido afirmar que o indivíduo é melhor ou pior, mais ou menos crítico, por ser leitor.

Voltando à questão acerca das indicações de leitura validadas para atestar sua verdadeira prática, nessas produções audiovisuais não é considerada apenas a leitura que se faz em grande quantidade, sob a forma do livro impresso e preferencialmente de renomados autores da alta literatura. Também são legitimados muitos tipos de leitura e muitas maneiras de ler. ${ }^{14}$

Um dos vídeos sintomáticos com relação à indicação de outros tipos de leitura que não aqueles comumente conhecidos, em se tratando de campanhas de incentivo à leitura, é o intitulado "Ler em 15 lições". ${ }^{15}$ Nele, inicialmente, apresentam-se 15 razões pelas quais a leitura ajuda nos estudos. Posteriormente são elencados outros tipos de leitura validados para se atestar a verdadeira prática de leitura, tal como o excerto transcrito abaixo: 
Ler em outras línguas

Ler livros virtuais

Através do computador

Há a leitura de sinais ou libras

Há a leitura em braile

Tem também o audiobook

E a leitura de receitas

Leitura de bula de remédio

Leitura de figuras

E a minha preferida... A leitura no banheiro.

Figura 7: Extraída do vídeo "Ler em 15 lições"

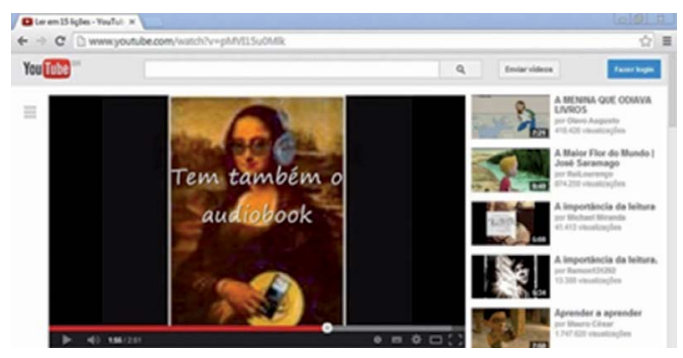

Assim como na apresentação dos 15 motivos ou lições pelos quais se crê que a leitura ajuda nos estudos, na continuação do vídeo a estratégia de escrita empregada é a da tentativa de ilustração do que é enunciado verbalmente na Protocampanha. Decorre daí que, por vezes, estabelecem-se algumas relações curiosas, como por exemplo, a representada abaixo.

A imagem escolhida para ilustrar o enunciado verbal Tem também o audiobook é a imagem da Mona Lisa de Leonardo da Vinci, obra mundialmente conhecida. Acreditamos que a escolha por representá-la caricaturalmente aqui, usando óculos escuros e fone de ouvido e portando o que seria um audiobook [sic] e mais uma espécie de chapéu amarelo se deve à tentativa de quebrar o ar de tradição e seriedade dessa pintura bem como da leitura sob a forma impressa, incutindo, em ambas, novidade e tecnologia.

Outra curiosidade no tocante a esse vídeo não diz respeito à relação estabelecida entre os enunciados que o compõem, mas ao que é efetivamente enunciado, como demonstrado abaixo:

Figura 8: Extraída do vídeo "Ler em 15 lições"

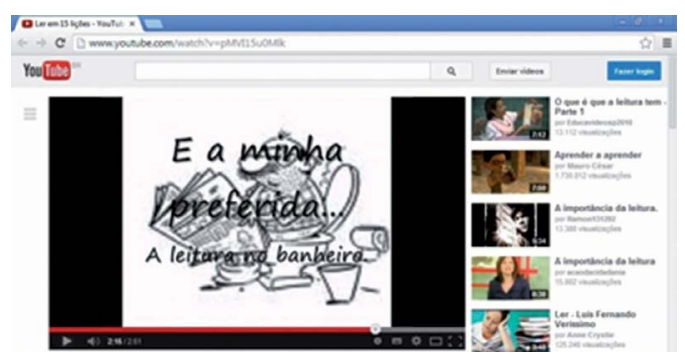

Desse modo, entre as muitas maneiras de ler elencadas nesse vídeo está também a leitura no banheiro. Acreditamos que o estranhamento bem como o efeito de sentido jocoso gerado por essa asserção, e corroborado pela imagem escolhida para ilustrá-la, deve-se ao fato de essa representação da leitura fugir aos estereótipos aceitos como verdadeiros em se tratando dessa prática, realizada normalmente em bibliotecas, escolas ou no interior da casa, e feita por leitores por vezes compenetrados, por outras com expressão tranquila e sorridente, mas sempre solene diante da entidade "livro" e da prática de leitura. Essa jocosidade também se deve ao fato de essa Protocampanha publicizar o impublicável, ou seja, apesar de essa prática de leitura ser comum, a referência a ela, principalmen- 
te em se tratando de uma campanha, não costuma ser explícita.

Assim, acreditamos que a estratégia de escrita empregada foi a da tentativa de aproximação e relativa dessacralização da prática e dos objetos por meio da contrariedade de padrões pré-definidos para a leitura, apresentando-a como atividade simples e rotineira a minha preferida.

\section{Considerações finais}

Buscamos demonstrar ao longo deste trabalho que, em grande parte tributária do modo como a leitura foi concebida historicamente e do modo como foram se constituindo os dizeres autorizados sobre nós e de nós sobre nós mesmos, o imaginário de uma alegada crise da leitura no nosso país, relacionado diretamente com a questão do consumo de livros, é recorrente.

Ainda que oriundo de discursos que remontam historicamente, segundo Márcia Abreu (2001b), ao Brasil Colônia, tal imaginário é remanente na contemporaneidade e faz com que muitos e variados setores da sociedade tomem para si a responsabilidade pela criação e veiculação de campanhas em prol da leitura.

Levantamos, assim, algumas representações discursivas da leitura e do leitor brasileiro contemporâneo manifestas nessas campanhas, e apreendidas por meio da análise de vídeo-campanhas de incentivo à leitura que circulam no site do YouTube.

Assim, tendo em vista os discursos contemporâneos acerca da leitura como prática redentora e transformadora da realidade social, discutimos quais são as formas de ler e os objetos de leitura validados que assegurariam os benefícios que essa prática promove, vinculados à sua capacidade de transformar a realidade social de um indivíduo. No tocante às Campanhas, as leituras validadas para atestar sua verdadeira prática são aquelas que se apropriam do objeto livro impresso, com frequência, de gêneros específicos, em particular de orientação literária e/ou ficcional de modo geral (principalmente quando se trata da leitura para crianças e jovens). Com relação à postura leitora esperada, que pode ser apreendida por meio das formas de abordagem do leitor-interlocutor desses vídeos, pressupõe-se estar se dirigindo a leitores "especializados" ou então adultos, maduros, que têm a obrigação de formar mais leitores (crianças, jovens). No tocante às Protocampanhas, se, assim como os vídeos das Campanhas, indicam a necessidade de que se leia sempre e muito e sob a forma impressa de livros, principalmente de alta literatura, também reproduzem outro imaginário, que por sua vez valida outros tipos de leitura feitas em diversos objetos culturais e de vários gêneros, ainda que, ao fazê-lo, de certo modo, ilustre algumas dessas asserções com imagens de livros sob sua forma impressa.

Também pudemos constatar que nelas, diferentemente das Campanhas, em sua maioria, a relação estabelecida com o interlocutor não pressupõe estar se dirigindo a bons leitores que precisam ser 
convencidos da necessidade de formar mais leitores, mas o outro é caracterizado como o lugar da falta e, portanto, é necessário convencê-lo a se tornar leitor para que tenha acesso à redenção e à transformação de sua realidade social.

\section{Discourses about reading: an analysis of video campaigns of this practice}

\section{Abstract}

In this article we aim to review some representations of contemporary reading practices present in videos to promote reading posted on the YouTube website. Based on principles of Discourse Analysis and Cultural History of Reading, we will develop our analysis in order to describe some discursive representations made about reading in these videos.

Keywords: Reading; Encourage reading; audiovisual campaigns. Videos from YouTube

\section{Notas}

1 A pesquisa Retratos da Leitura no Brasil, encomendada pela Câmara Brasileira da Indústria do Livro (CBL), Sindicato Nacional das Editorias de Livros (Snel), Associação brasileira de editores de livros (ABRELIVROS) encontra-se em sua terceira edição (2012) e se auto declara como o mais completo estudo acerca do perfil do leitor brasileiro. Apresenta dados que indicam que os brasileiros leem em média 4 livros ao ano (incluindo os didáticos), número que corresponde a um decréscimo de consumo de livros em comparação com a mesma pesquisa realizada em 2008 na qual se levantou o número de 4,7 livros ao ano por brasileiro. A pesquisa, embora consulte os leitores de forma ampla sobre o que leem, não contabiliza a leitura de qualquer texto, interessando-se ex- clusivamente em levantar dados sobre a leitura e o consumo de livros por habitante.

2 Os pesquisadores do LIRE - Laboratório de Estudos Interdisciplinares das Representações discursivas do leitor brasileiro contemporâneo - dedicam-se à análise de representações do leitor, em especial do leitor popular, em projetos desenvolvidos em nível de TCC, Iniciação Científica, Iniciação à Docência (PIBID), Mestrado, Doutorado e Pós-doutorado. Para acesso a informações e trabalhos de pesquisadores do grupo $\mathrm{cf}$. $>$.

3 O YouTube, junção das palavras do idioma inglês "You" e "Tube" que em português seria alguma coisa como "você transmite", é um site, fundado em 2005 por Chad Hurley, Steve Chen e Jawed Karim, três então funcionários da PayPal, que foi adquirido em 2006 pelo Google, e que, como o próprio nome sugere, permite aos usuários da rede compartilharem vídeos de diversas origens, qualidades, tamanhos, com pessoas do mundo todo por meio dessa plataforma. O site é popular junto aos internautas justamente pelo fato de viabilizar que qualquer pessoa no mundo que conte com aparelhos para produção dos vídeos e um computador com internet possa carregar e compartilhar seus vídeos, exceto os protegidos por copyright, utilizando os formatos Adobe Flash e HTML5.

4 Enunciados extraídos de vídeos que compõem nosso corpus de análise.

5 Dada a dificuldade em se trabalhar com objetos de origem virtual tendo em vista a facilidade com que são postados, mas também retirados da rede, optamos por baixar do site do YouTube os vídeos que compõem nosso corpus de análise e arquivá-los na memória do computador a fim, única e exclusivamente, de garantir que pudéssemos ter acesso a eles mesmo que não estivessem mais disponíveis na internet.

$6 \quad$ É importante ressaltar que tais enunciados que nos serviram de títulos das subcategorias não são veiculados ipsis litteris nos vídeos, mas podem ser depreendidos por meio de paráfrases efetuadas em relação aos enunciados que os compõem uma vez que "pode-se dizer que ela[s] constitui[em] a evocação lateral daquilo que se sabe a partir de outro lugar e que serve para pensar o objeto da proposição de base" (PÊCHEUX, 1988, p. 111).

7 Conforme orientações no site do banco, clientes e não clientes poderiam receber a doação de livros, que seria efetuada mediante o preenchimento de um cadastro no site do banco, que 
então enviaria um kit com três livros infantis para o endereço da inscrição.

8 Disponível em: <http://www.youtube.com/ watch?v=FGVx6Y8DaUc $>$.

9 Disponível em: <http://www.youtube.com/watc $\mathrm{h} ? \mathrm{v}=\mathrm{LSqH} \mathrm{xxKqUNs \& feature=}=$ related $>$.

10 Disponível em: <http://www.youtube.com/ watch?v=yFtdZ5J8yJA $>$.

11 Disponível em: <http://www.youtube.com/ watch?v=ySHtEcKC9Ws $>$.

12 Disponível em: <http://www.youtube.com/ watch?v=pMVI15u0Mlk>.

13 Disponível em: <http://www.youtube.com/ watch?v=5D3BO7DyQ3M $>$.

14 Enunciado extraído do vídeo "Ler em 15 lições".

15 Disponível em: <http://www.youtube.com/ watch?v=pMVI15u0Mlk>.

\section{Referências}

ABREU, M. Diferentes formas de ler. Disponível em: <http://www.unicamp.br/iel/memoria/Ensaios/Marcia/marcia.htm $>$. Acesso em: 09 ago. 2013. (2001a)

Diferença e desigualdade: preconceitos em leitura. In: MARINHO, Marildes (Org.). Ler e navegar: espaços e percursos da leitura. Campinas: Mercado de Letras; ALB, 2001b. p. 139-157.

BARZOTTO, V. H.; BRITTO, L. P. L. Promoção X Mitificação da Leitura. In: Boletim informativo da $A L B$, Campinas, n. 3, ago. 1998.

BAUMAN, Z. Cultura como conceito. In: . Ensaios sobre o conceito de cultura. Rio de Janeiro: Zahar, 2012. p. 83-154.

BRITTO, L. P. L. Máximas impertinentes. Disponível em: <http://www.leiabrasil.org. br/old/material_apoio/pdfs/LuizBritto.pdf>. Acesso em: 10 ago. 2013.

CHARTIER, R. Uma trajetória intelectual: livros, leituras, literaturas. In: ROCHA, J. C. C. (Org.). Roger Chartier: a força das representações: história e ficção. Chapecó: Argos, 2011. p. 21-53.
FOUCAULT, M. A ordem do discurso: aula inaugural no Collège de France, pronunciada em 2 de dezembro de 1970. São Paulo: Edições Loyola, 2012.

LAJOLO, M. Os leitores, esses temíveis desconhecidos. In: LAJOLO, M. Do mundo da leitura para a leitura do mundo. São Paulo: Ática, 2002. p. 33-40.

PÊCHEUX, M. Da filosofia da linguagem à teoria do discurso. In: Semântica e discurso: uma crítica à afirmação do óbvio. Campinas: Editora da UNICAMP, 1988. p. 850-139. 